\title{
Follow the Money not the Cash: Comparing Methods for Identifying Consumption and Investment Responses to a Liquidity Shock
}

\author{
Dean Karlan, Adam Osman and Jonathan Zinman*
}

August 2015

\begin{abstract}
Measuring the impacts of liquidity shocks on spending is difficult methodologically but important for theory, practice, and policy. We compare three approaches for tackling this question: directly asking borrowers how they spend proceeds from a loan (direct elicitation); asking borrowers using a list randomization technique (indirect elicitation) that allows them to answer discretely in cases where loan uses are at odds with lender policies or social norms; and, a counterfactual analysis in which we compare household and enterprise cash outflows for those in a treatment group, randomly assigned to receive credit, to a control group. The counterfactual analysis yields an estimate that about $100 \%$ of loan-financed spending is on business inventory. For the direct and indirect elicitations, we find evidence of both strategic misreporting and "following the cash": borrowers likely report what they physically did with cash proceeds, rather than counterfactual spending.
\end{abstract}

Keywords: loan use; consumption; investment; liquidity constraint; liquidity shock; fungibility; microcredit; microenterprise

JEL: D12; D22; D92; G21; O12; O16

\footnotetext{
* Contact information: Dean Karlan, dean.karlan@yale.edu, Yale University, IPA, J-PAL, and NBER; Adam Osman, aosman@illinois.edu, University Illinois at Urbana-Champaign; Jonathan Zinman, jzinman@dartmouth.edu, Dartmouth College, IPA, J-PAL, and NBER, Approval from the Yale University Human Subjects Committee, IRB0510000752 and from the Innovations for Poverty Action Human Subjects Committee, IRB \#07October-002. The authors thank financial support from the Bill and Melinda Gates Foundation, the Consultative Group for Assistance to the Poor (CGAP) and AusAID. The authors thank Kareem Haggag, Romina Kazadjian, Megan McGuire, Faith McCollister, Mark Miller, and Sarah Oberst at Innovations for Poverty Action for project management and field support throughout the project, and the senior management and staff at First Macro Bank and FICO Bank for their support and collaboration throughout this project. The authors retained full intellectual freedom to report and interpret the results throughout the study. All errors and opinions are those of the authors.
} 


\section{Introduction}

What are the impacts of liquidity shocks on the consumption and investment decisions of households and small businesses? Answers to this question have implications for the theory, practice, and regulation of credit, as well as for modeling intertemporal consumer choice. They shed light on perceived returns to investment, and on the extent to which constraints bind more for some types of household spending than others. Estimating impacts of liquidity shocks matters in many domains, for example in understanding household leveraging and deleveraging decisions in the wake of credit supply shocks, ${ }^{1}$ as well as evaluating interventions such as business grants, ${ }^{2}$ unconditional cash transfers, ${ }^{3}$ and microcredit expansions. ${ }^{4}$

Papers that track responses to liquidity shocks often focus on estimating medium- and longterm effects by measuring spending patterns, balance sheets, or summary statistics of financial conditions several months or years post-shock ${ }^{5}$. This reduced-form evidence has proven quite useful, but it often leaves the mechanism underlying any change unidentified. For each possible outcome observed many months post-liquidity shock, there are many paths from the liquidity change to that outcome. We compare different ways to identify what happens after the liquidity shock in order to identify the mechanisms driving the longer-term results. Identifying mechanisms is important because different paths can have different welfare implications.

To take an example closest to the setting we examine, many microcredit impact evaluations do not find significant effects of microcredit on enterprise scale or profitability one or two years post-intervention, even when the loans are targeted to microentrepreneurs. ${ }^{6}$ There are at least three possible explanations for these findings: (1) impacts only materialize over longer horizons due to compounded benefits, adjustment, etc. This hypothesis often motivates researchers and program advocates to highlight the value of longer-term outcome data; (2) microentrepreneurs do not actually invest marginal liquidity in their businesses, perhaps because they are credit constrained on the margin and have household investment or consumption smoothing with a higher expected return on investment (in utility terms) than business investment; (3) microentrepreneurs $d o$ invest microloan proceeds in their businesses, but these investments do not end up earning a positive net return.

\footnotetext{
${ }^{1}$ See e.g. Hall (2011), Eggertsson and Krugman (2012), and Mian and Sufi (2011).

${ }^{2}$ See e.g. Fafchamps et al (2014), Karlan, Knight and Udry (2013), and de Mel, McKenzie and Woodruff (2008).

${ }^{3}$ See e.g. Benhassine et al (Forthcoming), Blattman, Fiala and Martinez (2012), Haushofer and Shapiro (2013), Karlan et al. (2013).

${ }^{4}$ See e.g. Angelucci, Karlan and Zinman (2015), Attanasio et al (2015), Augsburg et al (2015), Banerjee et al (2015), Crepon et al (2015), Karlan and Zinman (2010), Karlan and Zinman (2011), Tarozzi, Desai and Johnson (2015), and an overview in Banerjee et. al. (2015)

${ }^{5}$ See e.g. Souleles (1999); Souleles (2002); Shapiro and Slemrod (2003); Johnson, Parker, and Souleles (2006); Agarwal, Liu, and Souleles (2007); Shapiro and Slemrod (2009); Sahm, Shapiro, and Slemrod (2012); Parker et al. (2013)

${ }^{6}$ See the studies cited in the above footnote, with the exception of Karlan and Zinman (2010), which examines untargeted consumer loans.
} 
The second and third explanations highlight the potential value of "following the money" from liquidity to spending decisions to reveal mechanisms underlying the paths from shock to outcomes. If the second explanation is accurate, that motivates further attempts to identify causes, consequences, and cures for credit constraints. If the third explanation is accurate that motivates further attempts to understand why entrepreneurs make investments that, ex-post at least, do not yield a positive net return on average (Moskowitz and Vissing-Jorgensen 2002; Anagol, Etang, and Karlan 2013; Karlan, Knight, and Udry 2013). ${ }^{7}$

But how exactly one might go about measuring spending in the immediate aftermath of a liquidity shock is not immediately obvious, methodologically speaking. There are several challenges.

Administrative data is rarely available for the appropriate sample, timeframe, or spending frequency, and even more rarely sufficiently comprehensive in its coverage of different types of consumption and investment. This makes survey design very important. Yet money is fungible, and household and (micro)enterprise balance sheets are often complex, making it difficult for respondents to identify the effects of the liquidity shock on their spending. Similarly, surveys that simply ask about past purchases produce noisy data, and measurement error increases with the length of the recall period (Nicola, Francesca, and Giné 2012). Moreover, surveys can produce biased, rather than merely noisy, data if respondents have justification bias, ${ }^{8}$ neglect to report some accounts to save time or effort, worry about surveyors sharing information with tax authorities or a lender that "requires" loans be used for particular purpose, or feel stigma about using debt for consumption purposes (Karlan and Zinman 2008). In short, data constraints, strategic reporting, and respondent (mis)perceptions may all make it difficult to follow the money.

We address these challenges by comparing results from three different methods for following the money obtained by borrowers subjected to a randomized supply shock from one of two microlenders in the Philippines. The three methods are: 1) direct elicitation (i.e., ask individuals how they will, or did, spend the money from a loan); 2) indirect elicitation (i.e., in a setting where someone may deliberately be untruthful, employ a survey technique that indirectly elicits their response); and 3) counterfactual analysis (i.e., compare cash outflows of those who borrowed to a counterfactual group that did not borrow).

We compare results from these three approaches, and consider the counterfactual analysis to yield evidence closest to the unbiased "truth". We examine three categories of loan uses: buying household goods, making enterprise investments, and paying down other debt. The direct

\footnotetext{
${ }^{7}$ Now consider the opposite state of the world: say an evaluation of 12-month impacts does find that a microcredit expansion produces larger, more profitable businesses. The mechanism need not be investment in business assets per se (inventory, physical capital, etc.) Rather, it could be investments in human capital (training, health, child care, etc.) that enable the entrepreneur or business "helpers" from her family to be more productive.

${ }^{8}$ E.g., my business did not grow from last year to this year, so I won't report (to the surveyor, or even perhaps to myself) that I actually did try to grow my business by investing in new assets earlier this year.
} 
elicitation questions ask about (intended) loan usage with questions along the lines of: "Will you/did you spend at least $\$ X$ of your loan on Y?" We ask these questions using four different enumerator and timing combinations: by bank staff at application and shortly after the disbursal of the loan, and by independent surveyors two weeks and two months after loan disbursal. The indirect elicitation questions employ a "list randomization" technique that makes it feasible for respondents to respond truthfully to sensitive questions without actually revealing details about their behavior (Karlan and Zinman 2012). This is important in our setting because the lenders require that loan proceeds be used for business purposes only. Our counterfactual analysis takes advantage of a randomized trial in which marginal applications were randomly assigned to either treatment or control. Then, at both two weeks and two months post-randomization, independent surveyors asked about all cash outflows from the individual's household or business that exceeded a certain amount, and compare treatment to control to estimate the impact of the liquidity shock on specific outcomes.

Comparing results across these methods sheds light on several questions. We infer how borrowers believe they should report their loan usage by comparing results across the four direct elicitation combinations. We infer how borrowers actually perceive the impact of the loan on their spending decisions (versus how they should report it) using indirect elicitation (the list randomization). And we infer how these perceptions, at least as elicited, differ from actual spending: the counterfactual analysis which compares responses to short-run spending questions across treatment and control groups. ${ }^{9}$

We find important differences, particularly for paying down other debt. Only $2.3 \%$ of borrowers report to the bank that they use loan proceeds to pay down other debt. Yet $19.1 \%$ (s.e. $=4.9 \%$ ) of our treatment group implicitly (via list randomization) reports doing so. Thus many perceive themselves to be paying down other debt, but do not report this to bank (naturally, since this would be frowned upon by the bank). However, counterfactual analysis suggests that the misreporting is actually closer to the truth, once fungibility is taken into account: only $1.6 \%$ (s.e. $=2.9 \%)$ of individuals actually paid down more debt relative to the control group. Similar results hold for spending on household items (although the results are less precisely estimated).

We estimate that the treatment effect on spending is entirely on business investment, specifically inventory. This average treatment effect can account for the entire average loan amount two weeks post-randomization, with even larger but more noisily estimated treatment effects at two months post-randomization. This result highlights how our preferred method of identifying counterfactual spending can complement longer-run follow-up data; e.g., in our setting, it will be interesting to see whether the short-run increases in inventory translate into long-run increases, and into higher profits.

\footnotetext{
${ }^{9}$ Counterfactual analysis in this case means comparing the difference in spending between treatment and control two weeks and two months post-randomization. We find that the difference in spending between the groups is about the same as the average loan provided to the treatment group by the bank.
} 
Why do people think they have flouted bank rules by spending on non-business purposesassuming that list randomization elicits perceived truthful responses- even though our counterfactual analysis suggests that they have not? We suspect that they respond in a more proximate, mechanical sense by following the cash: I took the loan proceeds and bought $\mathrm{X}$ with the cash (even if $\mathrm{X}$ would have been bought anyhow, through some other means). This finding highlights the risks of making inferences based on direct or indirect survey questions about loan uses. These sorts of questions appear in many surveys and have been used to make inferences like "most borrowers use payday loans to cover ordinary living expenses over the course of months, not unexpected emergencies over the course of weeks.",10

All told, our key contributions are methodological. Our study highlights the limits of direct and indirect survey questions about loan uses, and the value of short-run, high-frequency data collection on substantial outflows following a liquidity shock.

\section{Market Overview}

We collected data with the cooperation of two different banks in the Philippines, one in Metro Manila (covering mostly peri-urban areas) and another in northern Luzon. Both banks are for-profit institutions that offer individual liability microloans at about $60 \%$ APR. Loan sizes range from 5,000 pesos to 50,000 pesos, with a mean (median) of 13,996 $(10,000)$ in our sample. Loan maturities range from three to six months, with weekly repayments of principal and interest. Both banks require that applicants have an existing business, and be between 18 and 65 years old.

The Metro Manila bank has operated in the region since the 1960s. It had microloans outstanding to about 2,700 borrowers as of July 2013. This portfolio represents a small fraction of its overall lending, which also includes larger business and consumer loans, and home mortgages. Until the end of 2012, the bank's microlending activities received subsidized technical assistance from a USAID-funded program. ${ }^{11}$ The second bank has operated in mostly rural areas of northern Luzon since the 1980s. It had microloans outstanding to 26,000 borrowers in 2011 and offers other financial products as well.

The microloan market in the Philippines is somewhat competitive, as described in Karlan and Zinman (2011). There are informal options as well, including moneylenders. For our purposes the key fact is that that rejected borrowers do not simply obtain credit elsewhere: our banks' random assignments to credit actually do produce a substantial change in the total/net borrowing of applicants (see Section III-F below).

\footnotetext{
${ }^{10}$ http://www.pewtrusts.org/en/research-and-analysis/reports/2012/07/19/who-borrows-where-they-borrow-and-why For a recent example from a developing country context, see Groh and McKenzie (2014) which examines a macroinsurance scheme tied to a credit product, and, to be fair, acknowledges the difficulty of making inferences from survey questions on loan usage.

${ }^{11}$ The program was administered by Chemonics, Microenterprise Access to Banking Services (MABS).
} 
Our sample is comprised of 1661 marginal loan applicants who were randomized into loan approval or denial (see Section III-B for details on the randomization). Table 1 Column 1 provides baseline descriptive statistics gleaned from loan applications. $85.1 \%$ of the sample are women, $71.2 \%$ are married, and $32.9 \%$ are college educated. ${ }^{12}$. The average applicant is 41.7 years old and has owned her business for 6.6 years. Nearly half of the businesses are "sari-sari" (corner/convenience) stores. Average weekly cash flow in the businesses is 5,491 pesos (a bit more than \$125).

\section{Methods and Results}

\section{A. Overview}

To better understand how borrowers deploy loan proceeds, and report thereon, we follow individuals from when they first apply for a loan until two months later. By that endpoint, we suspect that most of any proceeds will have been spent; this seems like a reasonable assumption given the high interest rates and short maturities. Along the way we use a variety of different methods to try to get at the same underlying question: how did the loan change the client's spending relative to a counterfactual in which the loan was not available?

The data come from four different interactions, with the same individual, over the course of about two months. Figure 1 summarizes the timeline and the data collected in four distinct steps: (1) an application for a bank loan by the individual (direct elicitation); (2) a short survey of approved applicants at their first repayment, administered by a loan officer (direct elicitation); (3) a questionnaire by an independent surveyor two to three weeks after the loan application (direct and indirect elicitation methods, and cash outflows for counterfactual analysis) (4) a questionnaire by an independent surveyor about two months after the loan application (direct elicitation and cash outflows for counterfactual analysis).

In principle, with a larger sample size, testing different elicitation methods would be better done across-subjects than within-subjects, to avoid the possibility that subjects prefer to give consistent responses. Note that such an effect pushes against our core finding that responses differ in interesting ways across elicitation methods. ${ }^{13}$ Thus our results may underestimate the true extent to which elicitation methods influence inferences about the uses of marginal liquidity.

\section{B. Sample Creation and Randomization}

Our sample is comprised of 1,661 marginally creditworthy microloan applicants to the two banks described in Section II. Individuals applied from one of 16 bank branches at the Northern Luzon lender, or 8 branches at the Metro Manila lender, between July 2010 and March 2012.

\footnotetext{
${ }^{12}$ Females were not directly targeted by the bank. Enterprises of this size in the Philippines have greater female ownership; larger loans are serviced by a different part of the bank.

${ }^{13}$ On the other hand, if respondents notice they are being asked the same question in different manners they may instead change their answer if they believe that they are asked again because they provided the "wrong" answer the first time. This would bias us towards finding an effect.
} 
Each loan application is digitized by bank staff and credit-scored by underwriting software. For the purposes of this study, relatively small numbers of applicants with the highest (lowest) scores were automatically approved (rejected). The remaining applicants (about $85 \%$ of the pool) were randomly assigned to approval (with $90 \%$ probability) or rejection (with $10 \%$ probability). ${ }^{14}$

This random allocation of loans to marginal clients serves as the identifying instrument for our analysis of the expenditure data described in Sections III-E and III-F below. Table 1 Column 3 confirms that the treatment and control groups are observably identical, in a statistical sense: regressing treatment assignment on treatment strata and the complete set of baseline characteristics in Table 1, we do not reject the hypothesis that the characteristics are jointly uncorrelated with treatment assignment ( $\mathrm{p}$-value $=0.477)$.

\section{Data Collection Step 1: At Application, by Loan Officer (Direct Elicitation)}

The first pieces of data on loan uses come from loan applications. Applications are extensive and take the form of loan officers interviewing applicants, reviewing their documents, and entering data into a small netbook computer. This process typically takes at least an hour to complete and includes questions on income, household composition, assets and liabilities, and business cash flows.

The banks added three questions on loan uses to their applications at our behest. The applicant was first asked: (1) Do you plan to spend 5,000 pesos or more of your loan on any one household item? ${ }^{15}$ (2) Do you plan to spend 2,500 pesos or more of your loan on servicing any other debt? Later the applicant was asked to provide a full listing of intended usage of the loan. The former two questions are designed to identify non-trivial non-business uses of loan proceeds, keeping in mind that the median loan size is 10,000 pesos, and that borrowers may split loan proceeds among several different types of expenditures. ${ }^{16}$

This first step allows us to see how the applicants report their intended loan usage to the banks. These data will not be very informative about true intentions if applicants believe that their responses may affect the lender's decision. For example, applicants might reasonably infer that banks prefer to lend exclusively for business purposes, and answer no to the questions about household and refinancing uses, regardless of their true intentions.

Table 2 Column 1 shows that very few applicants report non-businesses loan uses on their loan applications. Only $1.8 \%$ report planning to use their loan on a household transaction of 5,000 pesos or more (Panel A), and only $2.3 \%$ report planning to use their loan to pay down debt

\footnotetext{
${ }^{14}$ Although a 50/50 split to treatment and control would have provided more statistical power, the banks were interested in aggressively expanding their pool of borrowers.

${ }^{15}$ Exchange rate at time of surveys was US $\$ 1=43$ Philippine Pesos.

${ }^{16}$ Appendix Figure A1 shows the kernel density of requested loan amounts. The amounts asked about (5000 and 2500 pesos) were meant to be large enough to be remembered clearly and to avoid everyday purchases, but small enough to capture potential uses of loan proceeds.
} 
of 2,500 or more (Panel B). ${ }^{17}$ Column 1 shows results for the treatment group only, for comparability with subsequent analysis. Results do not change if we include the control group.

Is the low reported prevalence of non-business uses on loan applications driven by strategic underreporting? Results below from steps 3 and 4 suggest yes, although only to a point. Before detailing those results we examine whether borrowers change their reporting behavior to the bank after they obtain a loan.

\section{Data Collection Step 2: At First Loan Repayment, by Bank Credit Officer (Direct Elicitation)}

The second pieces of data on loan uses come from a very short survey, administered by loan officers to a subset of borrowers, at the time of first repayment (about one week after loan disbursal). The loan officers asked two questions designed to parallel the key questions from the application: (1) Did you spend, or do you plan to spend, 5,000 pesos or more of your loan on any one household item? (2) Did you spend, or do you plan to spend, 2,500 pesos or more of your loan on servicing any other debt?

This step allows us to check for differences between what applicants and borrowers tell the bank. We might see such differences if applicants misreported strategically in the first step and the main driver of that behavior was concern about getting approved for the first loan. ${ }^{18}$ On the other hand, several factors push against finding differences, including repeat contracting, and any desire among borrowers to appear consistent in their reporting behavior.

We find that the reported prevalence of non-business uses post-loan is essentially unchanged from the loan application. Less than one percent report using their loan on a large household transaction, while $2.9 \%$ report using it to pay down other debt. ${ }^{19}$ This step was implemented only at one bank and only for a short period of time and so the sample size is small, with only 238 borrowers surveyed. This is because data collection proved onerous for the bank, and the bank discontinued it after we observed the strong similarity in reporting behavior between this step (post-loan) and step one (application).

\section{E. Data Collection Steps 3 and 4: 2-Week and 2-Month Surveys, by Independent Surveyor (All three methods)}

\footnotetext{
${ }^{17}$ As we show in section 2 of the paper our randomization was successful and so comparing the reported loan use intentions of the treatment and control group will not be informative at this point. The only place where comparing the responses is useful is in columns 5 and 7 , reported spending.

${ }^{18}$ It is worth considering how our inferences will be affected if borrowers change their mind over time about how to use loan proceeds. First, note that each of the independent surveys (two weeks and two months) does not suffer from this potential problem - each survey uses multiple elicitation methods, administered at the same time. Second, it is unclear why mind-changing would be asymmetric; e.g., for every person that changes their mind from a business use to a household use, we might well expect someone else to make the opposite change. .

${ }^{19}$ The loan officers also asked the borrowers what they primarily spent their loans on and every borrower replied that they spent it on their business.
} 
The third and fourth pieces of data on loan uses come from two surveys, administered by an independent surveyor about two weeks and two months after loan application, of both treatment and control group individuals. Surveyors located individuals at their place of business or home and invited them to take a survey on behalf of Innovations for Poverty Action (IPA), a research organization. Surveyors were not aware of any connection to the banks. Surveyors informed people in the sample frame that IPA obtained a list of potential survey respondents from a database of local businesses. ${ }^{20}$

Both surveys focus on direct elicitation of loan uses and the measurement of all recent substantial outflows, although the second survey is a bit shorter. Both were administered by the same surveyor. The scripts for key questions are reproduced in Appendix 1. Relative to the twoweek survey, measuring outflows at two months has the potential advantage of allowing more time for all loan proceeds to be spent. It also has several potential disadvantages: more time for the control group to find alternative sources of financing (weakening power), a longer recall period (increasing measurement error), and/or more time for any short-run returns on investment to affect spending decisions (confounding inferences about the direct effect of borrowing on spending).

Eighty-five percent of our initial sample of 1,661 completed the first (two-week) survey. Table 1 Column 6 shows that treatment assignment does not significantly affect two-week survey completion. There are small differences between the treatment and control groups, for instance the proportion who have graduated from high school is slightly higher in the treatment group, but a test of joint significance shows that baseline characteristics to not predict treatment status. Sixty-seven percent of our initial sample completed the second (two-month) survey. Table 1 Column 9 shows that treatment assignment does not significantly affect two-month survey completion. A test of joint significance also confirms that baseline characteristics do not predict treatment status among those who responded to the two month survey.

The two-week survey begins with questions about basic demographics, health and savings. These introductory questions are designed to mitigate the likelihood that respondents infer any connection or association between the survey and their recent loan (application). The surveyor then asked the respondent for details on any outstanding loans, starting with the most recent one. Respondents reporting a loan were then asked about their deployment of loan proceeds using three different methods.

First, the surveyor explicitly asked the two key loan use questions: (1) Did you spend 5,000 pesos or more of your loan on any one household item? (2) Did you spend 2,500 pesos or more of your loan on servicing any other debt? We expect the proportion of "yeses" here to be higher than those reported to the bank, since incentives for strategic misreporting to an independent

\footnotetext{
${ }^{20}$ The goal was to be truthful yet also mask the relationship with the specific partnering bank. The surveyors themselves had no knowledge of the bank connection. It is possible that after multiple similar interactions some respondents could have made the connection between the bank's questions and the surveyor questions.
} 
surveyor should be lower. Table 2 Column 2 shows that this is indeed the case, to some extent. $5.5 \%$ of individuals report using a loan for a large household expense; compared to $1.8 \%$ on the loan application (the 3.7 percentage point difference has a p-value $<0.001$, s.e. $=0.006$ ). $7.7 \%$ report using the loan to pay down other debt, compared to $2.3 \%$ on the loan application (the 5.4 percentage point difference has a $\mathrm{p}$-value $<0.001$, s.e. $=0.009$ ). Of course, borrowers may still underreport non-business uses if such uses are stigmatized, or if borrowers suspect a connection between the surveyor and their bank. Such concerns motivate our second elicitation method.

Second, the surveyor administered a list randomization exercise to elicit estimates of grouplevel proportions of respondents using loan proceeds to pay down debt or buy household goods. List randomization is used across various disciplines to mitigate the underreporting of socially or financially sensitive information (Karlan and Zinman 2012). The procedure asks a randomlyselected half of the respondents to report the total number of "yes" answers to four innocuous binary questions (Appendix 1), and the other half to report the total number of "yes" answers to the same four innocuous binary questions plus a fifth sensitive one. We did this separately for the two different loan use questions: (1) I spent over 5,000 pesos of my loan of a single household transaction" and (2) "I spent more than 2,500 pesos of my loan to pay down other debt." We then estimate the proportion responding "yes" to the sensitive (loan use) question by subtracting the mean count of "yeses" for those who had only had the four innocuous questions from the mean count for those who had all five questions (including a loan use question). ${ }^{21}$ As expected, list randomization produces substantially higher estimates of non-business uses (Table 2 Column 3). We infer that $11.5 \%$ (s.e. $=5.6 \%$ ) of respondents report spending at least 5,000 pesos of their loan proceeds on a single household transaction, with $19.1 \%$ (s.e. $=4.9 \%$ ) spending at least 2,500 of their loan proceeds on paying down other debt. ${ }^{22}$

All told, the results in Columns 1-3 suggest that elicitation method can have substantial effects on how borrowers report loan uses. Borrowers report more non-business uses when asked by an independent surveyor rather than a bank, and still more when they can report anonymously. The results suggest that list randomization, administered by an independent surveyor, produces relatively accurate estimates of how borrowers perceive their loan uses.

These results thus far do not address the question of how borrower perceptions accord with the reality that is most interesting to many researchers, practitioners, and funders: what did the respondent buy that they would not have in the absence of the marginal loan? Fungibility may

\footnotetext{
${ }^{21}$ Those who do not report an outstanding loan instead are assigned the mean count of the short-list (innocuous, non-loan use questions only) group. Results are nearly identical if we instead drop these non-borrowers.

${ }^{22}$ Those that respond positively to all items in the larger list of 5 questions may be less worried about anonymity as they are identifying themselves as having used the funds in the sensitive manner. Nonetheless, we continue to see under-reporting by this group: 7 out of the 1245 individuals surveyed answered " 5 " on the debt question. Of these 7 , only 1 directly reported they used their loan on refinancing debt when asked. For the household question, 10 out of 1245 individuals answered " 5 ", of those only 3 directly reported that they used their loan on a large household expenditure. Additionally, this potential for a lack of anonymity would make it less likely for us to find an effect across elicitation methods.
} 
make it difficult to construct survey questions that elicit that counterfactual. For example, loan proceeds may be used to purchase inventory in the proximate sense of cash from a lender being handed over to a supplier. But if the business owner would have purchased that inventory anyway, the marginal (counterfactual) purchase could be something else entirely; e.g., perhaps the cash flow that would have been used to purchase inventory is now used to purchase health care for an ailing family member.

The difficulty of identifying the counterfactual of interest motivates our third type of survey question: we ask each respondent to list each household and business outflow greater than 1,000 pesos from the past two weeks (type and amount). ${ }^{23}$ (Note the lack of any reference to loans or loan proceeds: this question asks about spending more broadly.) Together with the random assignment of loan approvals, we use responses to this question to identify the counterfactual: the impacts of the marginal loan on consumption and investment. We treat the results from this method of elicitation as close to the "truth" regarding where the funds went. Although this is an assumption, we find below that the average difference in spending between treatment and control lines up with the average increase in credit availability, lending credence to the idea that this method provides us insight into how marginal liquidity gets spent.

Table 2 Column 4 reports the results, which show a striking lack of impact on non-business spending. The treatment (loan approved) and control (loan rejected) groups have identical proportions (0.133) of respondents reporting one or more household expenses $>=5000$ pesos, for a treatment effect of zero (s.e. $=0.030) .{ }^{24}$ For debt pay down, the treatment group has a slightly higher proportion $(0.142$ vs. 0.126$)$, but the 1.6 percentage point difference (s.e. $=0.029)$ is not statistically significant. ${ }^{25} \mathrm{We}$ find similar results, on a much higher base, in the two-month survey. ${ }^{26}$ Regarding the base, many more respondents directly report non-business uses, whether directly (Column 5) or on the outflow list (Column 6). ${ }^{27}$ Regarding the counterfactual of interest, when we compare the treatment group to the control group we find that the control group has an equally high base, statistically speaking. $22.7 \%$ of the treatment group report spending at least 5,000 pesos on any one household transaction while $18.0 \%$ of the control group does so. This

\footnotetext{
${ }^{23}$ Subjects were not asked to keep a diary of expenses or anything similar. They were simply asked to recall their spending over 1000 pesos over the requested time frame, without any prompts for specific expense types. This may lead to under-reporting of spending, which we would be concerned about if the treatment group was more likely to under-report since they have more spending in general due to the positive liquidity shock of the loan. This may bias us toward underestimating spending of the treatment group, especially on sensitive items. Since the estimated difference in spending between treatment and control is within the range of the additional liquidity provided by the lender, we believe this bias to be small.

${ }^{24}$ ). The cut-off at 5,000 pesos allows us to check for large household expenditures and lines up with the direct questions that are asked of the borrowers. If we instead use a 1,000 peso cut-off we get an increase of 0.026 in treatment $(\mathrm{SE}=0.045)$.

${ }^{25} \mathrm{We}$ are implicitly using the random assignment as an instrument for borrowing over the subsequent two weeks. The top rows of Table 3 confirm that the instrument is a powerful one; e.g., a treatment group member is 16 percentage points more likely to have a formal sector loan than a control group member.

${ }^{26}$ The higher base could be due to respondents taking more than 2 weeks to fully spend their loan proceeds, and/or to respondents' increased comfort with the survey or surveyor.

${ }^{27}$ We did not include list randomization on the two-month survey.
} 
difference of 4.7 percentage points (s.e. $=0.037$ ) is not statistically significant (p-value $=0.210$ ). Similarly, $23.7 \%$ of the treatment group reports spending more than 2,500 pesos on other debt ${ }^{28}$ while $19.7 \%$ of the control group does so. This difference of 4.1 percentage points $($ s.e. $=0.039)$ is not statistically significant.

When comparing results across different elicitation methods it is important to note that some confidence intervals are large, in particular for the estimates coming from the list randomization. For instance, while the point estimate for the proportion of individuals who indirectly admit to spending 5,000 pesos or more of their loan on a single household transaction is $(0.115)$, the confidence interval is $(0.005,0.225)$. At the same time, when we instead estimate the proportion of individuals who have spent more than 5,000 pesos on a single household item using the data from their expenditure listing we get a point estimate of (0.000), with a confidence interval of (0.059,0.059). If we compare the point estimate derived from the expenditure listing to the confidence interval derived from the list randomization we find that the point estimate lies just outside of the confidence interval. If instead we compare the two confidence intervals we do find overlap. On the other hand, when we compare the confidence intervals in the debt repayment case where the list randomization confidence interval is $(0.095,0.287)$, and the expenditure listing confidence interval is $(-0.041,0.073)$ we do not find overlap. ${ }^{29}$ Although some estimates are imprecise, overall we do have sufficient power to infer some differences between what people report they did with the loan (Column 2), with what they perceive they did with the loan (Column 3) and what they actually did with the loan (Column 4), to be informative. ${ }^{30}$ We do not aim to put too much emphasis on any one estimate, but instead, to draw attention to how different methods provide different results.

Taken together, the results in Table 2 highlight several key findings. Substantively, there is little evidence of substantial non-business uses of microenterprise loans in this particular setting. This is surprising, given low impact on business growth in general from microcredit (Angelucci, Karlan, and Zinman 2015; Attanasio et al. 2015; Augsburg et al. 2015; Banerjee et al. 2015; Crépon et al. 2015; Karlan and Zinman 2010), findings from a prior study with one of the lenders here that marginal borrowers decrease investment in their microenterprises (Karlan and Zinman 2011), and mounting concerns that people "over-borrow" to finance consumption (Zinman 2014).

\footnotetext{
${ }^{28}$ It may seem peculiar that the proportion of respondents who report spending more than 2,500 on debt pay down in the explicit question asked by the surveyor (column 6) is higher than the proportion that report this when listing out their spending over the past 2 months (column 7). This may be due to the fact that the outflow list has a 1,000 peso threshold, so if someone pays off debt in increments $<1,000$ pesos but a total amount $>=2,500$ pesos, the outflow list would miss this, whereas that direct question might capture it.

${ }^{29}$ This simple comparison of confidence intervals does not take into account any covariance between the different questions.

${ }^{30}$ These results hold when we restrict the sample to only those reached for both the two week and two month interview. Results are also robust to using surveyor fixed effects.
} 
Methodologically, we find that borrower reporting responds strongly to the elicitation method, and that direct elicitation of loan uses does not produce credible evidence on a key counterfactual - what borrowers purchased that they would not have purchased in the absence of a loan. Rather, we identify the counterfactual using random assignment of credit access coupled with short-term follow-up measurement of substantial outflows.

\section{F. So Where Does the Money Go?}

If the marginal expenditure financed by a loan is not on a household item or other debt service (Table 2), it presumably is on some sort of business investment. Can we actually detect an increase in business investment, or do measurement error or reporting biases make it futile to attempt to follow the money with survey data?

Tables 3 and 4 suggest that our methods can in fact identify the marginal spending: business inventory, in this case. We switch from the mean comparisons in Table 2 (Columns 4 and 6) to regressions to improve precision, and estimate OLS intention-to-treat (ITT) models, with HuberWhite standard errors, of the form:

$$
Y_{i t}=\alpha+\beta * \text { treatment }_{i}+\delta * F E_{i t}+\varepsilon
$$

Where $i$ indexes individuals, and $t$, time. The binary variable, treatment $=1$ if $i$ was randomly assigned to loan approval, and $\mathrm{FE}$ is a vector of randomization strata (a bank indicator, credit score category, application month-year, and the survey month-year). $Y$ is an outcome measuring borrowing (to show the magnitude of the first-stage) or spending, measured at either $t=2$ weeks or $t=2$ months post-random assignment. Because inferences about these outcomes may be influenced by outliers, we present results from three different functional forms: Column 1 estimates effects on the level of spending (in pesos); Column 2 "winsorizes" the data, recoding the top $1 \%$ of $Y$ 's to the $99^{\text {th }}$ percentile; and Column 3 "trims" the data, dropping observations in the top percentile of $Y$. We do not use $\log (Y)$ because most of our borrowing and spending variables have many zeros.

Table 3 shows treatment effects on different measures of $Y$ over the two weeks after random assignment. Table 4 shows treatment effects on the spending measures over the two months after random assignment.

The first panel of Table 3 shows that we have a strong first stage, similar to that found in Karlan and Zinman (2011) with the Metro Manila lender participating in this study. The treatment effect on the likelihood of having a loan from one of our partner banks is 0.33 (p-value $<0.001$, s.e. $=0.042$ ). This is measured using administrative data from the bank. The effect is $<1$ due to approved applicants in the treatment group deciding to not actually go ahead with the loan, and to control group applicants who managed to avail a loan anyway. The remaining outcomes are measured using the follow-up surveys. Treatment effects on measures of total formal sector borrowing are still statistically significant but about one-half the size on borrowing from our partner lenders, due in part to some control group individuals obtaining credit from 
comparable lenders, and in part to substantial underreporting of debt that is line with what we have found in other studies (Karlan and Zinman 2008; Zinman 2009; Zinman 2010; Karlan and Zinman 2011). ${ }^{31}$

The next panel of Table 3 estimates the treatment effect on total spending, as measured using our question asking respondents to list all outflows $>=1,000$ pesos during the past two weeks. Depending on our treatment of outliers, the estimate ranges from 4,996 to 5,696 pesos (with pvalues of $0.059,0.038$, and 0.028 and standard errors of 3,010,2,588, 2,136 respectively). Scaling up these estimates by the difference in borrowing rates from the administrative data (since that data is not subject to underreporting of debt), we get estimated treatment-on-thetreated effects of about 15,000-16,000 pesos. The average loan size is 14,601 pesos, suggesting that our two-week outflow questions do successfully follow the money. They also suggest that borrowers spend all loan proceeds within the first two weeks, which seems plausible given the high interest rate and short maturity.

The rest of Table 3 disaggregates spending into several categories of interest. We confirm the lack of significant effects on household spending and debt pay down found in the earlier means comparisons (Table 2). Most notably, we find increases in business expenditures, in magnitudes commensurate with the treatment effect on overall spending. Disaggregating business expenses into fixed assets, inventory, renovations, utilities, salaries, and other, we find evidence suggesting that the entirety of the (business) spending increase is due to inventory. The ITT estimates on inventory range from 3,738 to 6,045 depending on how we treat outliers, with pvalues of $0.005,0.008$, and 0.049 (s.e.s of 2,173, 2,013, and 1,914 respectively). The focus on inventory may be due to the 3-6 month loan amortization, which may be too short for other types of investments to produce the returns needed to service the debt. We do not mean to suggest that this is a general result, i.e. that microfinance leads to borrowers spending their credit on inventory. We only mean to highlight the insights that can be gained from this type of data collection and analysis.

Table 4 repeats the spending analysis using data from the two-month follow-up survey. The results are qualitatively consistent with the two-week results. ${ }^{32}$ Point estimates are again more than large enough to offer a complete accounting of the loan proceeds. The pattern of results on spending (sub-)categories again suggests that about $100 \%$ of marginal spending is on business inventory. There are two noteworthy differences between the two-month and two-week results. One is that the two-month results are less precise. This is most likely due to the relative difficulty of recalling spending over a two month period. The second is that the two-month point estimates on total business expenditure, and inventory, specifically, are much larger. This could be an

\footnotetext{
$3134 \%$ of those we know, from administrative data, to have a loan with one of our lenders do not report any outstanding formal sector loans at the two-week follow-up survey.

${ }^{32}$ When we compare the estimates from the two-week survey and the two-month survey we are comparing slightly different samples. If we restrict the two-week survey to just those that are also in the two-month survey we find similar, but less precise results, as our sample size decreases.
} 
artifact of wide confidence intervals or respondent reporting. Or it could be capturing a true multiplier whereby treated individuals reinvest increased profits from the initial inventory increase, or obtain additional financing from other sources, to further increase inventory.

In any case, the suggestion that quantitative effect sizes may differ substantially over as short a period as six weeks - two weeks vs. two months - highlights the utility of short-run and highfrequency follow-ups for capturing and interpreting spending dynamics in the aftermath of a liquidity shock.

\section{Conclusion}

Discussions of outcome measurement following liquidity shocks often focus on how longerrun data may be needed to measure key impacts (e.g., of investments that require longer gestation periods, or learning). We take a different tack, and test three different methods for measuring the short-run responses.

The first method uses direct elicitation questions about intended loan usage on the banks' loan applications, shortly after loan disbursal, and nearly identical direct questions asked of borrowers, by independent surveyors, with no link to the bank, two weeks and two months after loan disbursal. The second method uses indirect elicitation questions through two "list randomization" questions, asked by independent surveyors two weeks after disbursal, that make it feasible for respondents to respond truthfully to sensitive questions without actually revealing details about their behavior. The third method uses a counterfactual analysis via the lenders' randomizations and the two-week and two-month independent follow-up surveys, by comparing a listing of recent expenditures (with no reference to recent borrowing) across the treatment and control groups.

The results suggest three key findings in our setting. First, respondents report strategically. They report very little non-business uses of loan proceeds to the bank, significantly more to independent surveyors when asked direct questions, and yet significantly more to independent surveyors when presented with lists of statements that allow them to report what they believe to be the truth without directly revealing what they spent. Second, even when borrowers are more likely to respond with what they perceive to be the truth, their answers to questions about "did you spend X or more of your loan on..." are different than the counterfactual of greatest interest to economists and policymakers, where additional expenditure was actually spent. Third, we estimate that the treatment effect is actually entirely on business investment, specifically inventory. This treatment effect can account for the entire loan amount 2-weeks postrandomization, with even larger but more noisily estimated effects at 2-months postrandomization. 
We believe the main implication of our results is methodological: researchers should consider collecting spending data on both treatment and control subjects very shortly after an exogenous liquidity shock. In particular, our study highlights the value of shorter-run, highfrequency data collection on substantial outflows following a liquidity shock. To take just two examples, if we are interested in the possibility of over-borrowing, the methods used in this paper can be used to address the question of "over-borrowing on what"? In the settings studied here, the answer appears to be "not on consumption". If we are interested in why expanding access to microcredit does not reliably lead to business growth and increased profits, the methods here can be used to address the question "is this because borrowers invest in something else, or because they invest and fail?" In the settings studied in this paper it appears that any downstream lack of business growth is not for lack of trying.

Future work can build on this by combining estimates of liquidity shock spending responses with longer-term follow-up data. In our context, this will enable us to measure whether the shortrun investments in inventory produce long-run increases in profits and/or improvements in household outcomes. Another important question is whether alternative direct (and indirect) elicitation methods might help borrowers and researchers zero in on the key counterfactual, and encourage future work in this area. Perhaps asking "what did you spend your loan on that you would not have bought if you had not gotten a loan?" would produce the same inferences, at less expense, than a randomized experiment followed by elicitation of all major household and business outflows. 


\section{References}

Agarwal, Sumit, Chunlin Liu, and Nicholas S. Souleles. 2007. "The Reaction of Consumer Spending and Debt to Tax Rebates-Evidence from Consumer Credit Data." Journal of Political Economy 115 (6): 986-1019. doi:10.1086/528721.

Anagol, Santosh, Alvin Etang, and Dean Karlan. 2013. "Continued Existence of Cows Disproves Central Tenets of Capitalism?" National Bureau of Economic Research 19437 (September). http://www.nber.org/papers/w19437.

Angelucci, Manuela, Dean Karlan, and Jonathan Zinman. 2015. "Microcredit Impacts: Evidence from a Randomized Microcredit Program Placement Experiment by Compartamos Banco." American Economic Journal: Applied Economics 7 (1): 151-82. doi:10.1257/app.20130537.

Attanasio, Orazio, Britta Augsburg, Ralph De Haas, Emla Fitzsimons, and Heike Harmgart. 2015. "The Impacts of Microfinance: Evidence from Joint-Liability Lending in Mongolia." American Economic Journal: Applied Economics 7 (1): 90-122. doi:10.1257/app.20130489.

Augsburg, Britta, Ralph De Haas, Heike Harmgart, and Costas Meghir. 2015. "The Impacts of Microcredit: Evidence from Bosnia and Herzegovina." American Economic Journal: Applied Economics 7 (1): 183-203. doi:10.1257/app.20130272.

Banerjee, Abhijit, Esther Duflo, Rachel Glennerster, and Cynthia Kinnan. 2015. "The Miracle of Microfinance? Evidence from a Randomized Evaluation." American Economic Journal: Applied Economics 7 (1): 22-53. doi:10.1257/app.20130533.

Banerjee, Abhijit, Dean Karlan, and Jonathan Zinman. 2015. "Six Randomized Evaluations of Microcredit: Introduction and Further Steps." American Economic Journal: Applied Economics 7 (1): 1-21. doi:10.1257/app.20140287.

Benhassine, Najy, Florencia Devoto, Esther Duflo, Pascaline Dupas, and Victor Pouliquen. Forthcoming. "Turning a Shove into a Nudge? A 'Labeled Cash Transfer' for Education." American Economic Journal: Economic Policy

Blattman, Christopher, Nathan Fiala, and Sebastian Martinez. 2012. "Employment Generation in Rural Africa: Mid-Term Results from an Experimental Evaluation of the Youth Opportunities Program in Northern Uganda." SSRN Scholarly Paper ID 2030866.

Crépon, Bruno, Florencia Devoto, Esther Duflo, and William Pariente. 2015. "Estimating the Impact of Microcredit on Those Who Take It Up: Evidence from a Randomized Experiment in Morocco." American Economic Journal: Applied Economics 7 (1): 123-50. doi:10.1257/app.20130535.

De Mel, Suresh, David McKenzie, and Christopher Woodruff. 2008. "Returns to Capital in Microenterprises: Evidence from a Field Experiment." Quarterly Journal of Economics 123 (4): 1329-72.

Eggertsson, Gauti B., and Paul Krugman. 2012. "Debt, Deleveraging, and the Liquidity Trap: A FisherMinsky-Koo Approach." The Quarterly Journal of Economics 127 (3): 1469-1513.

Fafchamps, Marcel, David McKenzie, Simon Quinn, and Christopher Woodruff. 2014. "Microenterprise Growth and the Flypaper Effect: Evidence from a Randomized Experiment in Ghana." Journal of Development Economics 106 (January): 211-26. doi:10.1016/j.jdeveco.2013.09.010.

Groh, Matthew, and David McKenzie. 2014. "Macroinsurance for Microenterprises: A Randomized Experiment in Post-Revolution Egypt." SSRN Scholarly Paper ID 2502229. Rochester, NY: Social Science Research Network. http://papers.ssrn.com/abstract=2502229.

Hall, Robert E. 2011. "The Long Slump." American Economic Review 101 (2): 431-69. doi:10.1257/aer.101.2.431.

Haushofer, Johannes, and Jeremy Shapiro. 2013. "Welfare Effects of Unconditional Cash Transfers: Evidence from a Randomized Controlled Trial in Kenya." M.I.T. Working Paper. http://www.princeton.edu/ joha/publications/Haushofer_Shapiro_UCT_2013.pdf. 
Johnson, David S, Jonathan A Parker, and Nicholas S Souleles. 2006. "Household Expenditure and the Income Tax Rebates of 2001." American Economic Review 96 (5): 1589-1610. doi:10.1257/aer.96.5.1589.

Karlan, Dean, Ryan Knight, and Christopher Udry. 2013. "Consulting and Capital Experiments with Micro and Small Tailoring Enterprises in Ghana." Working Paper.

Karlan, Dean, Isaac Osei-Akoto, Robert Darko Osei, and Christopher R. Udry. 2013. "Agricultural Decisions after Relaxing Credit and Risk Constraints." Quarterly Journal of Economics, Forthcoming. doi:10.2139/ssrn.2169548.

Karlan, Dean, and Jonathan Zinman. 2008. "Lying About Borrowing." Journal of the European Economic Association, Journal of the European Economic Association, 6 (2-3): 510-21.

- - . 2010. "Expanding Credit Access: Using Randomized Supply Decisions to Estimate the Impacts." Review of Financial Studies 23 (1): 433-64.

- - . 2011. "Microcredit in Theory and Practice: Using Randomized Credit Scoring for Impact Evaluation." Science 332 (6035): 1278-84. doi:10.1126/science.1200138.

- - . 2012. "List Randomization for Sensitive Behavior: An Application for Measuring Use of Loan Proceeds." Journal of Development Economics 98 (1): 71-75. doi:10.1016/j.jdeveco.2011.08.006.

Mian, Atif, and Amir Sufi. 2011. "House Prices, Home Equity-Based Borrowing, and the US Household Leverage Crisis." American Economic Review 101 (5): 2132-56.

Moskowitz, T.J., and A. Vissing-Jorgensen. 2002. "The Returns to Entrepreneurial Investment: A Private Equity Premium Puzzle." American Economic Review 92 (4): 745-78.

Nicola, De, Francesca, and Xavier Giné. 2012. "How Accurate Are Recall Data? Evidence from Coastal India." SSRN Scholarly Paper ID 2027805. Rochester, NY: Social Science Research Network. http://papers.ssrn.com/abstract=2027805.

Parker, Jonathan A, Nicholas S Souleles, David S Johnson, and Robert McClelland. 2013. "Consumer Spending and the Economic Stimulus Payments of 2008." American Economic Review 103 (6): 2530-53. doi:10.1257/aer.103.6.2530.

Sahm, Claudia R., Matthew D. Shapiro, and Joel Slemrod. 2012. "Check in the Mail or More in the Paycheck: Does the Effectiveness of Fiscal Stimulus Depend on How It Is Delivered?" American Economic Journal: Economic Policy 4 (3): 216-50. doi:10.1257/pol.4.3.216.

Shapiro, Matthew D., and Joel Slemrod. 2003. "Consumer Response to Tax Rebates." American Economic Review 93 (1): 381-96. doi:10.1257/000282803321455368.

- - . 2009. "Did the 2008 Tax Rebates Stimulate Spending?" American Economic Review 99 (2): $374-$ 79. doi:10.1257/aer.99.2.374.

Souleles, Nicholas S. 1999. "The Response of Household Consumption to Income Tax Refunds." American Economic Review 89 (4): 947-58. doi:10.1257/aer.89.4.947.

Souleles, Nicholas S. 2002. "Consumer Response to the Reagan Tax Cuts." Journal of Public Economics 85 (1): 99-120.

Tarozzi, Alessandro, Jaikishan Desai, and Kristin Johnson. 2015. "The Impacts of Microcredit: Evidence from Ethiopia." American Economic Journal: Applied Economics 7 (1): 54-89. doi:10.1257/app.20130475.

Zinman, Jonathan. 2009. "Where Is the Missing Credit Card Debt? Clues and Implications." Review of Income and Wealth 55 (2): 249-65.

- - . 2010. "Restricting Consumer Credit Access: Household Survey Evidence on Effects Around the Oregon Rate Cap." Journal of Banking \& Finance 34 (3): 546-56.

- - . 2014. "Consumer Credit: Too Much or Too Little (or Just Right)?” Journal of Legal Studies 43 (S2 Special Issue on Benefit-Cost Analysis of Financial Regulation): S209-37. 


\section{Figure 1: Study Timeline}

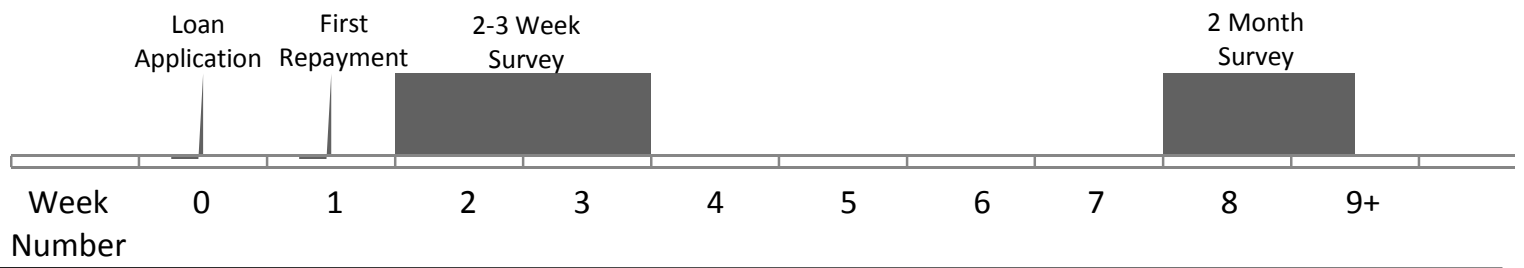

\section{Loan Activity \& Data Collection}

Week 0:
$\begin{aligned} & \text { Loan Activity: } \\ & \text { Applies for Loan } \\ & \text { Credit Score Calculated } \\ & \text { Loan Randomization } \\ & \quad \text { Implemented }\end{aligned}$
$\frac{\text { Data Collection }}{\text { (Bank Employee): }}$
Loan Use Questions
Intended Use Listing

\begin{tabular}{|c|c|}
\hline Week 1: & Weeks 2\&3: \\
\hline Loan Activity: & Loan Activity: \\
\hline $\begin{array}{c}\text { First Repayment } \\
\text { (For Treatment) }\end{array}$ & $\begin{array}{l}\text { Continued } \\
\text { Repayment } \\
\text { (For Treatment) }\end{array}$ \\
\hline Data Collection & \\
\hline (Bank Employee): & Data Collection \\
\hline Loan Use Questions & Independent \\
\hline Main Use of Funds & $\begin{array}{l}\text { Surveyor): } \\
\text { Loan Use Questions } \\
\text { List Randomization } \\
\text { Spending Outflows }\end{array}$ \\
\hline
\end{tabular}

$\frac{\text { Week 8: }}{\frac{\text { Loan Activity: }}{\text { Continued }}}$
Repayment
(For Treatment)
$\frac{\text { Data Collection }}{\text { (Independent }}$
$\frac{\text { Surveyor): }}{\text { Loan Use Questions }}$
Spending Outflows

Weeks 9-24:

Loan Activity:

Continued Repayment (For Treatment) 
Table 1: Orthogonality of Treatment to Applicant Characteristics and Attrition

\begin{tabular}{|c|c|c|c|c|c|c|c|c|c|c|c|c|}
\hline \multirow[b]{2}{*}{ Demographic variables } & \multicolumn{3}{|c|}{ Baseline } & & \multicolumn{3}{|c|}{ 2-Week Survey } & & \multicolumn{3}{|c|}{ 2-Month Survey } & \\
\hline & Control & Treatment & Difference & & Control & Treatment & Difference & & Control & Treatment & Difference & \\
\hline & (1) & $(2)$ & (3) & & (4) & $(5)$ & (6) & & (7) & (8) & $(9)$ & \\
\hline \multirow[t]{2}{*}{ Male } & 0.139 & 0.151 & 0.011 & & 0.114 & 0.139 & 0.025 & & 0.111 & 0.139 & 0.028 & \\
\hline & $\{0.394\}$ & $\{0.386\}$ & $(0.033)$ & & $\{0.380\}$ & $\{0.380\}$ & $(0.035)$ & & $\{0.380\}$ & $\{0.378\}$ & $(0.037)$ & \\
\hline \multirow[t]{2}{*}{ Age } & 40.987 & 41.809 & 0.821 & & 40.501 & 41.940 & 1.439 & $*$ & 41.058 & 42.357 & 1.299 & \\
\hline & $\{9.70\}$ & $\{9.12\}$ & $(0.79)$ & & $\{9.44\}$ & $\{9.10\}$ & $(0.84)$ & & $\{9.10\}$ & $\{9.17\}$ & $(0.89)$ & \\
\hline \multirow[t]{2}{*}{ Marital Status -- Single } & 0.137 & 0.084 & -0.052 & $*$ & 0.135 & 0.086 & -0.049 & & 0.141 & 0.072 & -0.069 & $* *$ \\
\hline & $\{0.363\}$ & $\{0.290\}$ & $(0.029)$ & & $\{0.361\}$ & $\{0.290\}$ & $(0.031)$ & & $\{0.290\}$ & $\{0.272\}$ & $(0.034)$ & \\
\hline \multirow[t]{2}{*}{ Marital Status -- Married } & 0.675 & 0.716 & 0.040 & & 0.684 & 0.719 & 0.036 & & 0.672 & 0.725 & 0.053 & \\
\hline & $\{0.459\}$ & $\{0.439\}$ & $(0.037)$ & & $\{0.453\}$ & $\{0.434\}$ & $(0.040)$ & & $\{0.434\}$ & $\{0.424\}$ & $(0.043)$ & \\
\hline \multirow[t]{2}{*}{ Marital Status -- Widowed/Separated } & 0.115 & 0.125 & 0.010 & & 0.109 & 0.126 & 0.017 & & 0.128 & 0.137 & 0.009 & \\
\hline & $\{0.294\}$ & $\{0.314\}$ & $(0.025)$ & & $\{0.277\}$ & $\{0.309\}$ & $(0.025)$ & & $\{0.309\}$ & $\{0.311\}$ & $(0.028)$ & \\
\hline \multirow[t]{2}{*}{ Education -- College } & 0.303 & 0.284 & -0.020 & & 0.301 & 0.258 & -0.042 & & 0.274 & 0.237 & -0.037 & \\
\hline & $\{0.486\}$ & $\{0.468\}$ & $(0.040)$ & & $\{0.486\}$ & $\{0.458\}$ & $(0.043)$ & & $\{0.458\}$ & $\{0.450\}$ & $(0.047)$ & \\
\hline \multirow[t]{2}{*}{ Education -- Some College } & 0.298 & 0.266 & -0.032 & & 0.281 & 0.277 & -0.004 & & 0.293 & 0.284 & -0.009 & \\
\hline & $\{0.447\}$ & $\{0.435\}$ & $(0.037)$ & & $\{0.438\}$ & $\{0.441\}$ & $(0.039)$ & & $\{0.441\}$ & $\{0.444\}$ & $(0.043)$ & \\
\hline \multirow[t]{2}{*}{ Education -- Graduated High School } & 0.325 & 0.383 & 0.058 & $*$ & 0.325 & 0.391 & 0.066 & $*$ & 0.324 & 0.398 & 0.073 & $*$ \\
\hline & $\{0.423\}$ & $\{0.470\}$ & $(0.036)$ & & $\{0.422\}$ & $\{0.473\}$ & $(0.039)$ & & $\{0.473\}$ & $\{0.475\}$ & $(0.042)$ & \\
\hline \multirow[t]{2}{*}{ Education -- Some High School or Less } & 0.074 & 0.067 & -0.008 & & 0.095 & 0.074 & -0.021 & & 0.109 & 0.081 & -0.028 & \\
\hline & $\{0.325\}$ & $\{0.293\}$ & $(0.027)$ & & $\{0.347\}$ & $\{0.301\}$ & $(0.031)$ & & $\{0.301\}$ & $\{0.307\}$ & $(0.034)$ & \\
\hline \multirow[t]{2}{*}{ Number of Dependents } & 1.869 & 1.895 & 0.026 & & 1.907 & 1.915 & 0.008 & & 1.947 & 1.939 & -0.008 & \\
\hline & $\{1.554\}$ & $\{1.448\}$ & $(0.130)$ & & $\{1.599\}$ & $\{1.463\}$ & $(0.146)$ & & $\{1.463\}$ & $\{1.464\}$ & $(0.164)$ & \\
\hline \multirow[t]{2}{*}{ Number of Employees } & 0.828 & 0.800 & -0.028 & & 0.723 & 0.786 & 0.063 & & 0.705 & 0.761 & 0.057 & \\
\hline & $\{2.024\}$ & $\{1.953\}$ & $(0.180)$ & & $\{1.412\}$ & $\{2.035\}$ & $(0.149)$ & & $\{2.035\}$ & $\{2.202\}$ & $(0.170)$ & \\
\hline \multirow[t]{2}{*}{ Age of Primary Business } & 6.451 & 6.647 & 0.196 & & 6.595 & 6.732 & 0.137 & & 6.392 & 6.888 & 0.496 & \\
\hline & $\{5.232\}$ & $\{6.095\}$ & $(0.443)$ & & $\{5.309\}$ & $\{6.056\}$ & $(0.485)$ & & $\{6.056\}$ & $\{6.163\}$ & $(0.520)$ & \\
\hline Primary Business Weekly Cashflow & 4950 & 5552 & 602 & & 4590 & 5334 & 744 & $*$ & 4540 & 5259 & 719 & $*$ \\
\hline & $\{5400\}$ & $\{6184\}$ & $(453)$ & & $\{4612\}$ & $\{5824\}$ & $(424)$ & & $\{5824\}$ & $\{5803\}$ & $(431)$ & \\
\hline Primary Business Location - Commercial & 0.305 & 0.385 & 0.080 & $* *$ & 0.322 & 0.384 & 0.062 & & 0.319 & 0.387 & 0.068 & \\
\hline & $\{0.468\}$ & $\{0.489\}$ & $(0.039)$ & & $\{0.473\}$ & $\{0.488\}$ & $(0.042)$ & & $\{0.488\}$ & $\{0.489\}$ & $(0.046)$ & \\
\hline Primary Business Location - Residential & 0.695 & 0.615 & -0.080 & $* *$ & 0.678 & 0.616 & -0.062 & & 0.681 & 0.613 & -0.068 & \\
\hline & $\{0.468\}$ & $\{0.489\}$ & $(0.039)$ & & $\{0.473\}$ & $\{0.488\}$ & $(0.042)$ & & $\{0.488\}$ & $\{0.489\}$ & $(0.046)$ & \\
\hline Primary Business Arrangment - Owned & 0.625 & 0.609 & -0.016 & & 0.606 & 0.615 & 0.009 & & 0.612 & 0.629 & 0.017 & \\
\hline & $\{0.481\}$ & $\{0.485\}$ & $(0.040)$ & & $\{0.484\}$ & $\{0.482\}$ & $(0.043)$ & & $\{0.482\}$ & $\{0.477\}$ & $(0.047)$ & \\
\hline Primary Business Arrangment - Rent & 0.327 & 0.340 & 0.013 & & 0.341 & 0.332 & -0.009 & & 0.335 & 0.319 & -0.016 & \\
\hline & $\{0.453\}$ & $\{0.463\}$ & $(0.037)$ & & $\{0.456\}$ & $\{0.458\}$ & $(0.040)$ & & $\{0.458\}$ & $\{0.451\}$ & $(0.044)$ & \\
\hline Primary Business Type - Retail & 0.235 & 0.235 & 0.000 & & 0.230 & 0.221 & -0.010 & & 0.217 & 0.219 & 0.002 & \\
\hline & $\{0.394\}$ & $\{0.404\}$ & $(0.033)$ & & $\{0.392\}$ & $\{0.394\}$ & $(0.035)$ & & $\{0.394\}$ & $\{0.389\}$ & $(0.037)$ & \\
\hline Primary Business Type - Small Grocery/Convenience Store & 0.522 & 0.462 & -0.060 & & 0.509 & 0.474 & -0.035 & & 0.498 & 0.480 & -0.018 & \\
\hline & $\{0.499\}$ & $\{0.500\}$ & $(0.041)$ & & $\{0.500\}$ & $\{0.500\}$ & 0.044 & & $\{0.500\}$ & $\{0.500\}$ & 0.048 & \\
\hline Primary Business Type - Wholesale & 0.013 & 0.020 & 0.007 & & 0.014 & 0.016 & 0.002 & & 0.019 & 0.012 & -0.007 & \\
\hline & $\{0.153\}$ & $\{0.162\}$ & 0.013 & & $\{0.165\}$ & $\{0.156\}$ & 0.015 & & $\{0.156\}$ & $\{0.145\}$ & 0.017 & \\
\hline Primary Business Type - Service & 0.093 & 0.134 & 0.040 & & 0.093 & 0.135 & 0.042 & & 0.107 & 0.148 & 0.041 & \\
\hline & $\{0.318\}$ & $\{0.348\}$ & 0.026 & & $\{0.315\}$ & $\{0.345\}$ & 0.028 & & $\{0.345\}$ & $\{0.345\}$ & 0.029 & \\
\hline Primary Business Type - Manufacturing & 0.015 & 0.022 & 0.007 & & 0.017 & 0.025 & 0.008 & & 0.007 & 0.019 & 0.011 & \\
\hline & $\{0.109\}$ & $\{0.143\}$ & 0.009 & & $\{0.117\}$ & $\{0.151\}$ & 0.010 & & $\{0.151\}$ & $\{0.139\}$ & 0.009 & \\
\hline Primary Business Type - Vending & 0.118 & 0.125 & 0.007 & & 0.137 & 0.127 & -0.010 & & 0.153 & 0.120 & -0.033 & \\
\hline & $\{0.302\}$ & $\{0.322\}$ & 0.025 & & $\{0.324\}$ & $\{0.324\}$ & 0.029 & & $\{0.324\}$ & $\{0.321\}$ & 0.033 & \\
\hline P-Value on joint F-test: all RHS covariates listed $=0$ & & & 0.4776 & & & & 0.5932 & & & & 0.4888 & \\
\hline Attrition & & & & & 0.142 & 0.155 & 0.013 & & 0.268 & 0.326 & 0.058 & \\
\hline & & & & & $\{0.351\}$ & $\{0.373\}$ & $(0.029)$ & & $\{0.444\}$ & $\{0.349\}$ & $(0.037)$ & \\
\hline Observations & 1661 & 1661 & 1661 & & 1388 & 1388 & 1388 & & 1095 & 1095 & 1095 & \\
\hline
\end{tabular}

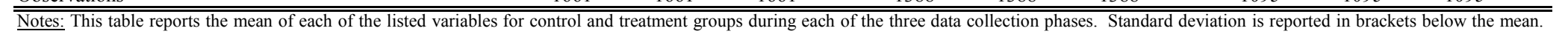

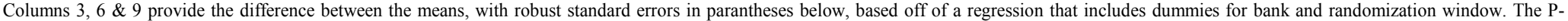

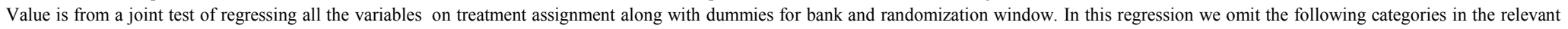

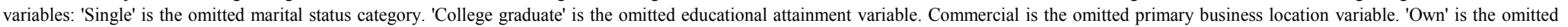
primary business property arrangement. 'Retail' is the omitted primary business type variable. 


\begin{tabular}{|c|c|c|c|c|c|c|}
\hline \multirow[t]{3}{*}{ Data Source: } & \multirow{2}{*}{$\frac{\text { Reported to Bank }}{\text { (1) }}$} & \multicolumn{3}{|c|}{ Reported in Survey 2-3 Week Following Randomization } & \multicolumn{2}{|c|}{$\begin{array}{c}\text { Reported in Survey } 2 \text { Months Following } \\
\text { Randomization }\end{array}$} \\
\hline & & (2) & (3) & (4) & (5) & (6) \\
\hline & $\begin{array}{l}\text { Proportion } \\
\text { reporting "yes" } \\
\text { on loan } \\
\text { application }\end{array}$ & $\begin{array}{c}\text { Proportion } \\
\text { reporting "yes" in } \\
\text { direct self-report } \\
\text { to independent } \\
\text { surveyor }\end{array}$ & $\begin{array}{l}\text { Implicit proportion } \\
\text { reporting "yes" from } \\
\text { list randomization. }\end{array}$ & $\begin{array}{l}\text { Proportion } \\
\text { reporting "yes" } \\
\text { for household } \\
\text { (Panel A) or } \\
\text { debt (Panel B) } \\
\text { outflows }\end{array}$ & $\begin{array}{c}\text { Proportion } \\
\text { reporting "yes" in } \\
\text { direct self-report } \\
\text { to independent } \\
\text { surveyor }\end{array}$ & $\begin{array}{c}\text { Proportion reporting } \\
\text { "yes" for household } \\
\text { (Panel A) or debt (Panel } \\
\text { B) outflows }\end{array}$ \\
\hline Specific survey question found in: & Appendix 1A & Appendix 1B & Appendix 1C & Appendix 1D & Appendix 1E & Appendix $1 \mathrm{~F}$ \\
\hline
\end{tabular}

Panel A: Household Expenditures:

Will/Did you use 5,000 pesos or more of your loan on any single transaction for your household?

$\begin{array}{cccc}\text { Treatment } & 0.018 & 0.055 & 0.115 \\ & (0.003) & (0.006) & (0.056)\end{array}$

0.115

0.133

0.216

0.227

Control

(0.003)

(0.009)

(0.013)

(0.013)

0.133

(0.028)

Treatment - Control

0.000

(0.030)

$0.035)$

1388

973

1095

Sample Size

1493

1245

0.191

0.077

0.023

(0.008)

(0.049)

0.142

(0.010)

0.126

(0.028)

0.016

(0.029)

1245

143

1245
0

0.325

0.237

$(0.014)$

0.197

$(0.036)$

0.041

(0.039)

973

Observations from Control

0

122

Notes: Column 1 considers our entire sample in treatment whether they were reached for the follow up survey or not. Columns 2 and 5 report the proportion responding "yes" to the direct question asked by the surveyor. If they didn't report a loan they were coded as saying "no". Column 3 looks at the difference in responses from a list randomization exercise on those in the treatment group that reported a loan, those that didn't report a loan were coded as saying "no". Columns 4 and 6 look at the actual spending reported by both treatment and control groups in each category and reports the difference between the two groups to take into account the fungibility of money. Results are robust to restricting the sample to those that completed all surveys, as well as including surveyor fixed effects. Robust standard errors in parentheses. 
Table 3: Actual Loan Use: Treatment Effects on Short-Term Cash Outflows (2-3 Weeks After Loan Application)

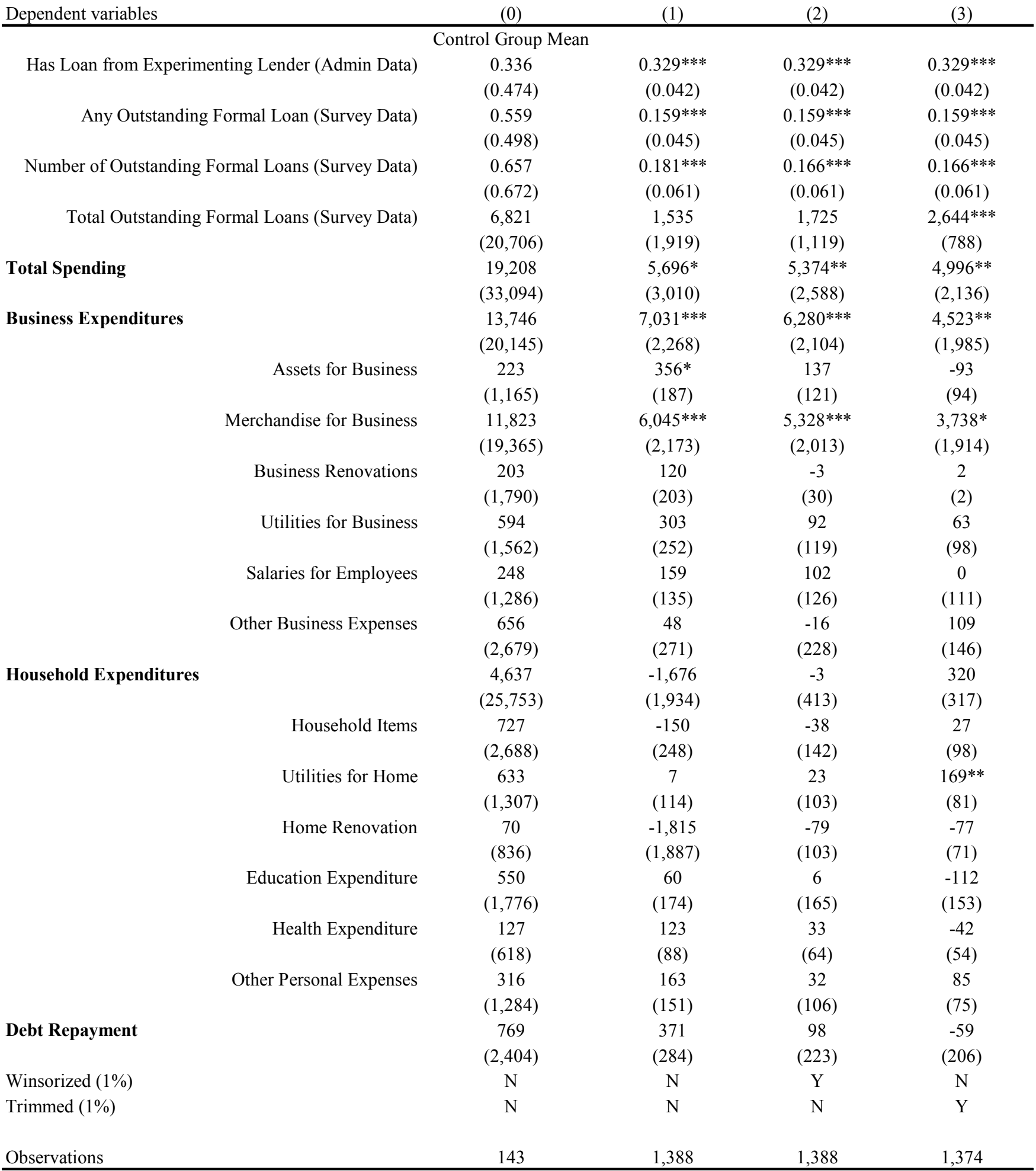

Notes: Each cell in columns 1-3 presents the treatment effect (i.e., the result on the variable 1=assigned loan) from a separate regression. Each regression includes controls for the bank and credit scoring band (i.e., the probability of assignment to treatment), and application month and survey month fixed effects. Results are robust to not including the fixed effects. Column 2 winsors the dependent variables at the top 1\%. Column 3 trims the dependent variables at the top 1\%. All self-reported borrowing measures are stock measures at the time of the 2 week survey. Loan and Spending amounts are in Philippine Pesos. Spending amounts are all outflows over 1000 pesos over the 14 days before the survey. Robust standard errors in parentheses, ${ }^{* *} \mathrm{p}<0.01,{ }^{* *} \mathrm{p}<0.05,{ }^{*} \mathrm{p}<0.1$ 
Table 4: Actual Loan Use: Treatment Effects on Long-Term Cash Outflows (2 Months After Loan Application)

Dependent variables

Total Spending

Business Expenditures

Assets for Busines
Merchandise for Busines
Business Renovation
Utilities for Busines
Salaries for Employee
Other Business Expense

\section{Household Expenditure}

\author{
Household Items \\ Utilities for Home \\ Home Renovation \\ Education Expenditure \\ Health Expenditure \\ Other Personal Expenses
}

\section{Debt Repayment}

Winsorized (1\%)
Trimmed (1\%)

Winsorized $(1 \%)$
Trimmed $(1 \%)$

Observations
(0)

Control Group Mean

$$
70,840
$$

$(143,029)$

60,665

$(138,764)$

320

$(2,098)$

56,496

$(134,126)$

943

$(7,257)$

1,246

$(3,184)$

765

$(3,518)$

896

$(2,669)$

6,837

$(15,260)$

1,303

$(4,884)$

1,370

$(2,222)$

1,015

$(7,345)$

834

$(2,629)$

1,565

$(10,770)$

866

$(3,581)$

3,240

$(13,943)$

N

$\mathrm{N}$

122
(1)

23,577

$(17,046)$

20,826

(16,518)

28

(229)

19,726

(16,075)

$-561$

(828)

237

(382)

584

(500)

813

(525)

699

$(1,746)$

287

(503)

$-32$

(225)

1,065

$(1,254)$

386

(283)

$-767$

(874)

164

(432)

1,719

(1,618)
(2)

13,849

$(13,643)$

11,092

$(13,295)$

15

(154)

9,748

$(13,094)$

$-241$

(168)

26

(235)

195

(374)

46

(274)

$-63$

$(1,204)$

345

(349)

$-47$

(207)

$-25$

(284)

288

(268)

$-43$

(213)

2

(264)

622

(1,087)
(3)

$22,209^{* *}$

$(8,868)$

$18,774 * *$

$(8,363)$

$-45$

(94)

$17,978 * *$

$(8,018)$

$-83$

(71)

117

(174)

$-172$

(316)

$-160$

(252)

457

(901)

273

(275)

30

(185)

$-196$

(136)

147

(247)

$-3$

(132)

17

(198)

387

(775)

\section{Y}

N

N

$\mathrm{N}$

Y

1095

1084

Notes:Each cell in columns 1-3 presents the treatment effect (i.e., the result on the variable 1=assigned loan) from a separate regression. Each regression includes controls for the bank and credit scoring band (i.e., the probability of assignment to treatment), and application month and survey month fixed effects. Results are robust to not including these fixed effects. Column 2 winsors the dependent variables at the top 1\%. Column 3 trims the dependent variables at the top $1 \%$. Spending amounts are in Philippine Pesos. Spending amounts are all outflows over 1000 pesos over the 2 months before the survey The two-month survey did not ask about borrowing, administrative data about borrowing is the same data used in Table 3 and so not reported here but results are substantively equivalent. Robust standard errors in parentheses, $* * * \mathrm{p}<0.01, * * \mathrm{p}<0.05,{ }^{*} \mathrm{p}<0.1$ 


\section{Appendix 1: Survey Questions}

\section{$1 A-\quad$ Bank Interaction}

Panel A: Will you use 5,000 pesos or more of your loan on any single transaction for your household?

Panel B: Will you use 2,500 pesos or more of your loan to pay down other debt?

$1 B-\quad 1^{\text {st }}$ Loan Payment \& 2 Week Survey

Panel A: Did you use 5,000 pesos or more of your loan on any single transaction for your household?

Panel B: Did you use 2,500 pesos or more of your loan to pay down other debt?

1C- List Randomization

Panel A:

Short Version:

As with our example, I will now read five statements. I would like you to tell me how many are true for you, but do not tell me which ones are true.

1. I have a washing machine in my home.

2. I am originally from this city.

3. I have completed one year or more of formal education post-high school.

4. My household owns a computer.

Long Version:

As with our example, I will now read five statements. I would like you to tell me how many are true for you, but do not tell me which ones are true.

1. I have a washing machine in my home.

2. I am originally from this city.

3. I have completed one year or more of formal education post-high school.

4. My household owns a computer.

5. I used 5,000 pesos or more of my loan on any single transaction for my household.

Panel B:

\section{Short Version:}

As with our example, I will now read five statements. I would like you to tell me how many are true for you, but do not tell me which ones are true

1. I have visited a hospital or clinic in the last six months.

2. I have more than three siblings.

3. I have purchased some type of insurance in the past five years. 
4. My household owns an air conditioner.

\section{Long Version:}

As with our example, I will now read five statements. I would like you to tell me how many are true for you, but do not tell me which ones are true

1. I have visited a hospital or clinic in the last six months.

2. I have more than three siblings.

3. I have purchased some type of insurance in the past five years.

4. My household owns an air conditioner.

5. I used 2,500 pesos or more of my loan to pay down other debt.

1D- 2 Week Survey

Please list all transactions of 1,000 pesos or more that you have made in the last 14 days. List each item with the amount that you spent.

1E - 2 Month Survey

Panel A: In the past two months, did you spend 5,000 pesos or more on any single transaction for your household?

Panel B: In the past two months, did you spend 2,500 pesos or more to pay down debt?

\section{F- 2 Month Survey}

Please list all transactions of 1,000 pesos or more that you have made in the last two months. List each item with the amount that you spent. 
Table A1: Orthogonality of List Randomization Group to Applicant Characteristics and Attrition

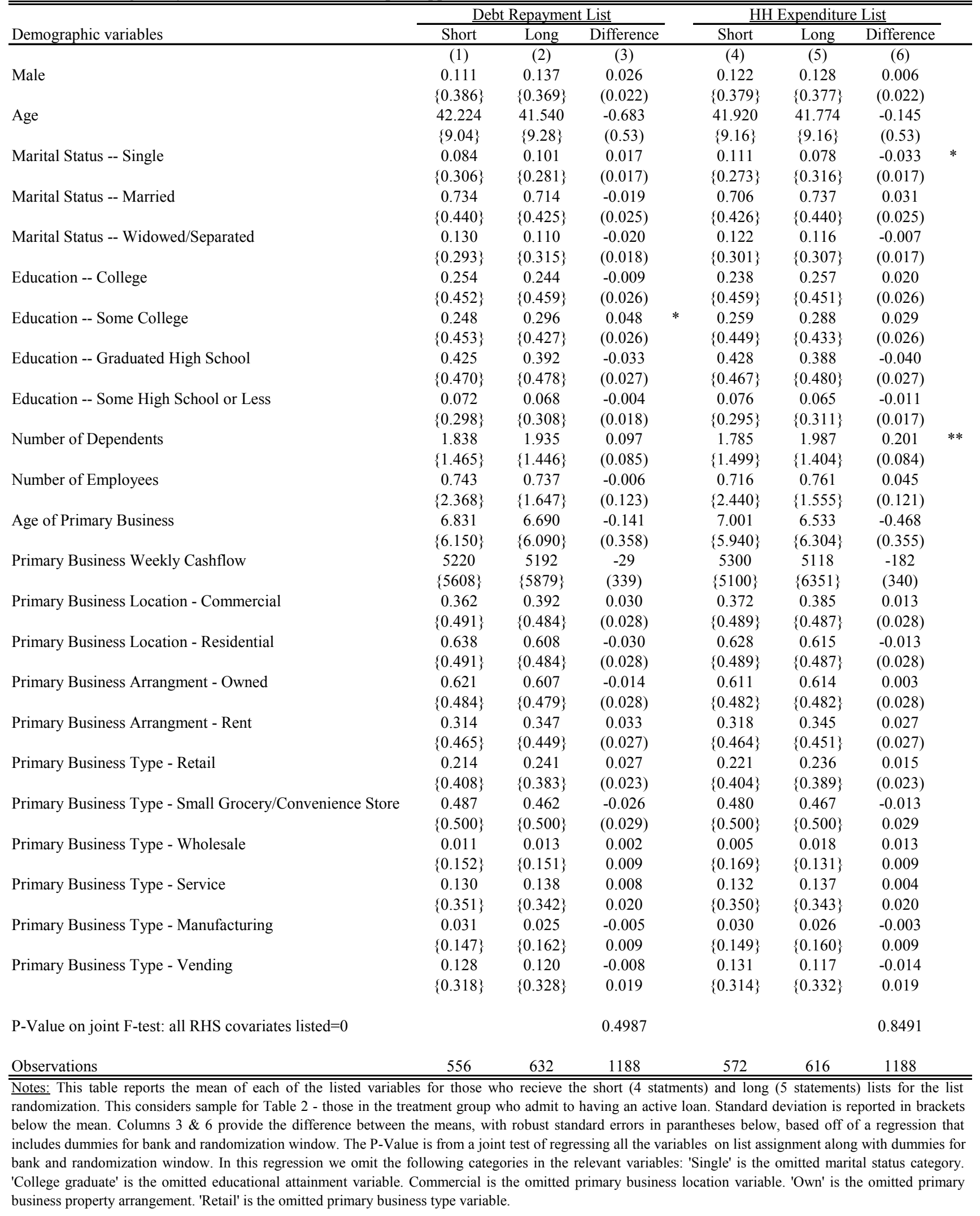


Figure A1: Kernel Density of Requested Loan Amount

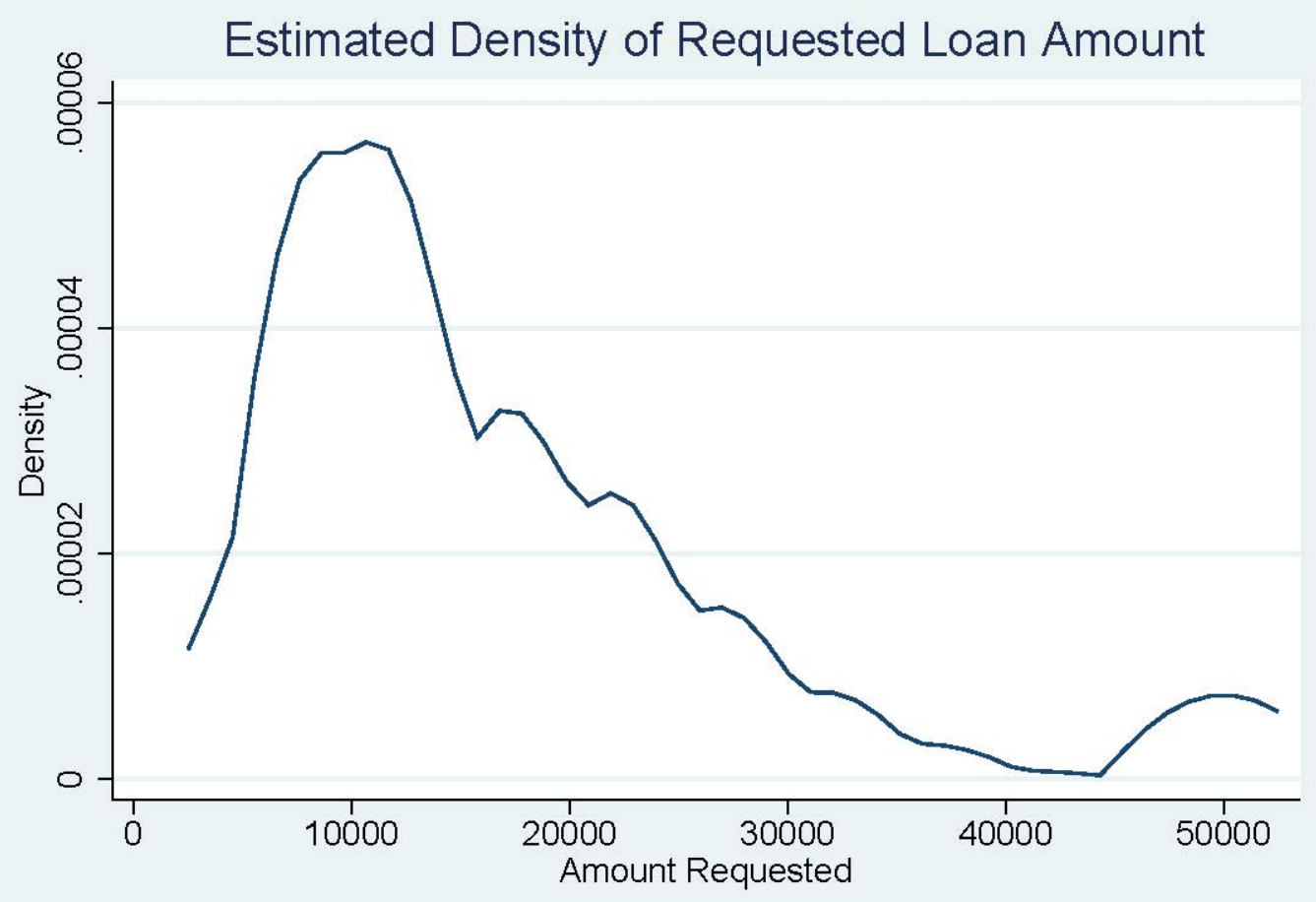

